\title{
Editorial
}

Dermatology

\section{Superimposed Segmental Hemangioma of Infancy}

\author{
Rudolf Happle \\ Department of Dermatology, University Medical Center Freiburg, Freiburg, Germany
}

\section{Key Words}

Hemangioma • Infancy $\cdot$ Segmental hemangiomas • Nonsegmental hemangiomas $\cdot$ Polygenic inheritance $\cdot$ Postzygotic mutation - Embryogenesis

\begin{abstract}
Background: Segmental hemangioma of infancy is sometimes associated with the development of multiple nonsegmental hemangiomas. Such co-occurrences have so far remained unexplained. Methods and Results: Pertinent reports were collected from the literature. To explicate such cases, the following concept is proposed. Hemangiomas of infancy reflect a polygenic predisposition. Nonsegmental lesions result from a mutational event occurring at a late stage of intrauterine life or after birth, whereas segmental hemangioma originates from loss of heterozygosity or some other mutational event arising at an early developmental stage. Conclusion: In this way, segmental hemangioma of infancy could be taken as a further example of the superimposed segmental manifestation of a polygenic skin disorder. Future molecular research may show whether this assumption holds true.

Copyright $\odot 2009$ S. Karger AG, Basel
\end{abstract}

\section{Introduction}

Hemangioma is the most common tumor of infancy [1]. As a general rule, these lesions tend to show spontaneous regression during childhood. Segmental hemangioma of infancy, however, shows a high frequency of complications [2,3]. This particular form of hemangioma has a prolonged growth phase [4] and tends to involute more slowly [2]. Moreover, segmental hemangiomas usually involve deeper adjacent structures as well as other organs (such as the brain or the spine) [2]. Here, some arguments are presented in favor of the assumption that segmental hemangioma of infancy may represent a further example of the superimposed segmental manifestation of a polygenic trait [5].

\section{Polygenic Basis of Infantile Hemangioma}

Infantile hemangioma (OMIM 602089) is commonly noted in neonates [1], which is why a previously assumed mendelian mode of inheritance $[6,7]$ can virtually be excluded. Recent molecular research has provided evidence that several genes - such as KDR (VEGFR2) at 4q12, FLT4 (VEGFR3) at 5q35.3, and ANTXR1 (TEM8) at 2p13.1 are involved in the susceptibility to this benign vascular tumor [7-9].

\section{KARGER \\ Fax +4161306 1234 \\ E-Mail karger@karger.ch}

www.karger.com
(C) 2009 S. Karger AG, Basel

$1018-8665 / 10 / 2202-0180 \$ 26.00 / 0$

Accessible online at: www.karger.com/drm
E-Mail rudolf.happle@uniklink-freiburg.de 

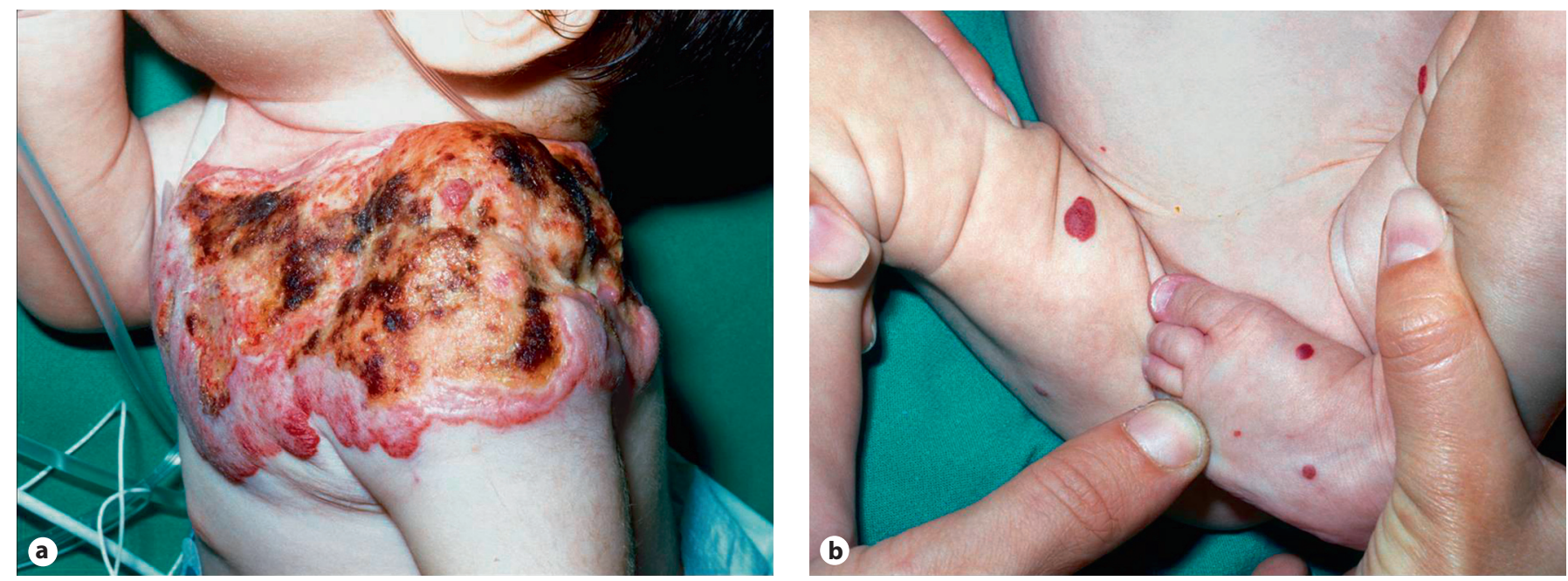

Fig. 1. Segmental hemangioma of infancy complicated by ulceration and infection in a 3-month-old girl. The large congenital lesion (a) was superimposed on multiple small nonsegmental hemangiomas (b) that developed during the first weeks of life (courtesy of Dr. Antonio Torrelo, Madrid, Spain).

\section{Intraindividual or Familial Co-Occurrence of Segmental and Nonsegmental Hemangioma}

Blei et al. [6] reported a familial case of hemangioma involving 4 generations. The youngest affected family member had 'an extensive hemangioma on her buttocks, perineum, and leg'. This large lesion was almost certainly a segmental hemangioma.

Hernández-Martín and Torrelo [10] described a 2month-old girl with a segmental hemangioma involving the right side of her face. MRI revealed a separate component of the segmental hemangioma involving the right paravertebral area and extending into the spinal canal through the foramina of several spinal nerves. In addition, several small hemangiomas measuring $0.5-2 \mathrm{~cm}$ were present on the right forehead, the abdomen, the anterior side of the neck and both arms.

Phan et al. [3] reported that 2 children with a large segmental hemangioma of the face 'also had a less prominent hemangioma on their trunk'.

An additional, so far unpublished, example of segmental hemangioma of infancy co-occurring with multiple nonsegmental hemangioma was observed by Dr. Antonio Torrelo (Madrid, Spain) and is shown in figure 1. A large segmental lesion was present at birth, whereas multiple small disseminated hemangiomas developed during the first weeks of life. In addition, multiple small hepatic hemangiomas were noted by sonography. Under high-dose steroid therapy, the small heman- giomas resolved quite quickly, and at 2 years of age the segmental hemangioma also disappeared with a good cosmetic result.

\section{Does Segmental Hemangioma of Infancy Represent a Superimposed Segmental Manifestation of a Polygenic Trait?}

The concept of superimposed segmental manifestation of common skin disorders was first proposed in 1991 to explain cases of pronounced linear psoriasis associated with milder nonlinear psoriatic lesions [11]. Recently, this theory was expanded to include numerous other common skin disorders with a polygenic basis, such as atopic dermatitis, lichen planus, granuloma annulare and vitiligo [5]. In an embryo carrying several predisposing genes, a mutational event occurring at an early developmental stage may result in loss of heterozygosity by which a heterozygous somatic cell may become homozygous or hemizygous for one of the predisposing genes. Alternatively, an early postzygotic new mutation may render a somatic cell heterozygous for a predisposing gene at an additional locus.

It is still possible that further clinical and molecular research may lead to other conclusions, but at this point in time it seems reasonable to assume that segmental hemangioma of infancy can be taken as a further example of segmental manifestation of a polygenic trait. This 
concept would explain why mixed cases of segmental and nonsegmental hemangioma occur, why the segmental lesions are rather pronounced, showing a high frequency of complications and being notoriously difficult to treat, and why some family members of an affected child may have nonsegmental infantile hemangioma.

\section{Acknowledgment}

I would like to thank Dr. Antonio Torrelo, Department of Dermatology, Hospital del Niño Jesús, Madrid, Spain, for kindly providing the photographs in figure 1 as well as a report of this case.

\section{References}

1 Walter JW, Blei F, Anderson JL, Orlow SJ, Speer MC, Marchuk DA: Genetic mapping of a novel familial form of infantile hemangioma. Am J Med Genet 1999;82:77-83.

$\checkmark 2$ Chiller KG, Passaro D, Frieden IJ: Hemangiomas of infancy: clinical characteristics, morphologic subtypes, and their relationship to race, ethnicity, and sex. Arch Dermatol 2002;138:1567-1576.

- 3 Phan TA, Adams S, Wargon O: Segmental haemangiomas of infancy: a review of 14 cases. Australas J Dermatol 2006;47:242247.

4 Brandling-Bennett HA, Metry DW, Baselga E, Lucky AW, Adams DM, Cordisco MR, Frieden IJ: Infantile hemangiomas with unusually prolonged growth phase: a case series. Arch Dermatol 2008;144:1632-1637.
Happle R: Superimposed segmental manifestation of polygenic skin disorders. J Am Acad Dermatol 2007;57:690-699.

6 Blei F, Walter J, Orlow SJ, Marchuk DA: Familial segregation of hemangiomas and vascular malformations as an autosomal dominant trait. Arch Dermatol 1998;134: 718-722.

7 Online Mendelian Inheritance in Man (OMIM). www.ncbi.nlm.nih.gov/omim (accessed 22 August 2009).
8 Walter JW, North PE, Waner M, Mizeracki A, Blei F, Walker JW, Reinisch JF, Marchuk DA: Somatic mutation of vascular endothelial growth factor receptors in juvenile hemangioma. Genes Chromosomes Cancer 2002;33:295-303.

-9 Jinnin M, Medici D, Park L, Limaye N, Liu Y, Boscolo E, Bischoff J, Vikkula M, Boye E, Olsen BR: Suppressed NFAT-dependent VEGFR1 expression and constitutive VEGFR2 signaling in infantile hemangioma. Nat Med 2008;14:1236-1246.

10 Hernández-Martín A, Torrelo A: Cutaneous and paravertebral infantile hemangioma: report of two cases. Pediatr Dermatol 2008;25: 193-195.

11 Happle R: Somatic recombination may explain linear psoriasis. J Med Genet 1991;28: 337. 